\title{
Offshore Aquaculture in India: Site Considerations and Challenges in Indian Coastal Conditions
}

\author{
Mohd Atif Siddiqui* \\ Buoyancy Consultants and Engineering LLP, India
}

Submission: February 02, 2018; Published: May 15, 2018

Corresponding author: Mohd Atif Siddiqui, Buoyancy Consultants and Engineering LLP, Goa, India, Email: atifsiddiqui2008@gmail.com

\section{Opinion}

Offshore aquaculture is the practice of marine farming where the fish farm cages are placed further from the shores into deeper ocean areas. This helps in increasing the size of farms, reduces danger of accidents with marine traffic and the waste from cage is easily washed away with stronger currents in the open ocean. One major disadvantage is that such a cage requires sophisticated technology and large investments. India has over $8000 \mathrm{~km}$ of coastline with great potential for development of mariculture. The exclusive economic zones which can extend up to at least 200 nautical miles from the coast, as shown in (Figure 1) (left), gives India a vast area for developing mariculture. Most of this potential remains underutilized as the locals and regional authorities lack the technical know-how and transfer of technology from academia to industry and local companies is extremely poor.

Offshore cage design present considerable challenges. These range from physical conditions, socio-economic condition in the region, legal regulations and viability of technical equipment and knowledge. We will discuss the physical conditions in detail later.
If we look at the social and economic challenges for a country like India, infrastructure and investment due to high risk factor, lack of proper regulation and technical knowledge. This results in open sea cage farming being mostly relegated to an unorganized sector.

These socio-economic challenges can be a factor that hinder open ocean aquaculture but the major reason still remains the technical challenges. Site selection is one of the most important decisions that needs to be considered. There often has to be a compromise between perfect offshore site conditions and local infrastructure available at the nearest port or on-shore establishments. Benetti et al. [1] has given an in-depth criteriabased site selection study for aquaculture cages. Here, we will mainly focus on the physical conditions at the site. Design wave is the highest wave height which a structure can withstand. Pérez et al. [2] do not recommend any cages, surface or submerged, for situations where the significant wave height exceed 8-9 meters. The critical loading on offshore cages, however, occurs due to a combination of waves, currents and the direction between waves and currents. (Table 1) shows the physical parameters to be considered and preferable values.

Table 1: Criteria for Site selection in offshore cages.

\begin{tabular}{|c|c|c|}
\hline Parameters & Preferred conditions & Notes \\
\hline Wave height $(\mathrm{m})$ & & Majority of the loads occur due to waves \\
\hline Current Velocity $(\mathrm{m} / \mathrm{s})$ & $<0.85 \mathrm{~m} / \mathrm{s}$ & Can be an important criterion for estimating drag force on the nets \\
\hline Depth profile & $30-100 \mathrm{~m}$ & $\begin{array}{c}\text { Has an impact on wave and current profile, also has effect ton mooring length for } \\
\text { moored cages }\end{array}$ \\
\hline Distance from shore & $<6 \mathrm{~km}$ & As we go farther away from shore, conditions will be come harsher \\
\hline
\end{tabular}

The major parameters for forces on cages are wave height, current velocity and depth consideration which in turn will affect the mooring loads. Estimation of force on a structure in a certain wave climate is a complex matter, and depends on geometry, flow direction etc. Generally, simplifications are made with calculations of forces and various loads. The modified Morison equation [1] can be used to calculate the hydrodynamic forces acting on the cage structure is shown in Eq. 1. 
$X_{h=} \frac{1}{2} \rho C_{D} A V_{R}\left|V_{R}\right|+\rho \nabla C_{M} \frac{\partial V_{R}}{\partial t}-\rho \nabla K_{M} \frac{\partial R}{\partial t}$

where $\rho$ is the density of sea water, CD the drag coefficient, KM the added mass coefficient, A projected area

Relative velocity, $V_{R}$ is defined as $V_{R}=V-R$. water particle velocity $V$ relative to cage velocity $R$ '. The first term on the right hand side of Eq. (1) is often regarded as the drag force, second term describes the added mass and the third term is called the inertia force. In addition to these wind forces must also be accounted for but are genrally small compared to wave loads. These loads are balanced by moorings to keep the cage within a suitable range.
The mooring tension will depend on depth and forces on the cage. Siddiqui et al. [4] discussed forces on an experimental cage located on the east coast. The study showed values for mooring forces and estimates of wave loads on cage structures. Parameters like depth of site, depth of cage, size of cage were varied. The results show that forces on cage structure varies considerably with depth. This makes the depth an imprtant criteria for site selection. (Figure 2) show wave height (left) and current velocity (right) conditions at a moored buoy on the west coast of India. These seem reasonable values along with the fact that west coast fo india is far less prone to cyclones as shown in (Figure 1) (right). Similar sites proviidng great potetnial can be found along the west caost of India.
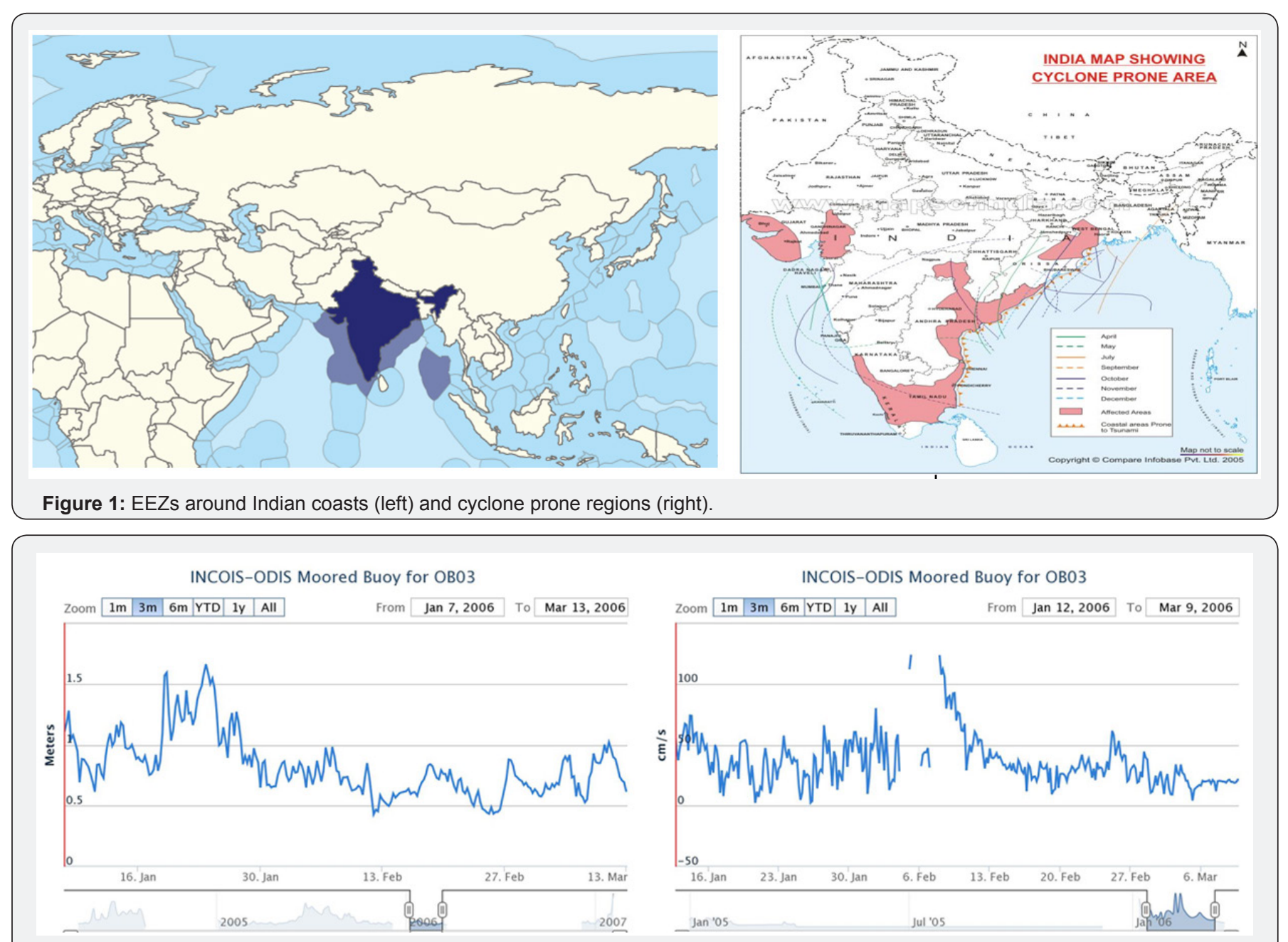

Figure 2: Wave height (left) and current velocity (right) at a particular location along west coast of India.

Sustainable aquaculture is currently the need in India as elsewhere. According to the MPEDA, there does currently not exist any cage-based production. This could be developed, as shown by a simplified example of physical condition analysis. In India, several experimental offshore cages for mariculture have been installed at several sites along the Indian coast. While some have been commercially successful, technical difficulties are often a commonissue. Modification in the cage design is done by trial and error to suit the local conditions. Training in mariculture is limited to the Central Marine Fisheries Research Institute in Cochin. Offshore aquaculture developments require a different cage design. Cages in offshore sites have to withstand harsher weather conditions, and the distance from the shore requires complex logistical systems.

In my opinion technology transfer, infrastructure development and promotion by the government will help sustainable aquaculture in India to feed a large part of the population. Careful site selection and planning can go a long way in achieving this aim. 


\section{Acknowledgement}

We used the moored buoy network established by the National Institute of Ocean Technology, Chennai data available with the Indian National Centre for Ocean information Services (INCOIS) (Figure 2) to show a sample site.

\section{References}

1. Daniel D Benetti, Gabriel I Benetti, José A Rivera, Bruno Sardenberg Brian Oapos, et al. (2010) Site Selection Criteria for Open Ocean Aquaculture. Marine Technology Society Journal 44(3): 22-35.
2. Pérez OM, Telfer TC, Ross LG (2003) On the calculation of wave climate for offshore cage culture site selection: A case study in Tenerife (Canary Islands). Aquacultural Engineering 29(1-2):1-21.

3. DeCew J, Tsukrov I, Risso A, Swift MR, Celikkol B, et al. (2010) Modeling of dynamic behavior of a single-point moored submersible fish cage under currents. Aquacultural Engineering 43(2): 38-45.

4. Siddiqui MA, Nagarajan V, Mukherjee CK (2014) Modeling the Forces and Motions of a Single Point Mooring Marine Aquaculture Cage. The Twenty-fourth International Ocean and Polar Engineering Conference 2014, Busan, Korea.

\section{Your next submission with Juniper Publishers will reach you the below assets}

- Quality Editorial service

- Swift Peer Review

- Reprints availability

- E-prints Service

- Manuscript Podcast for convenient understanding

- Global attainment for your research

- Manuscript accessibility in different formats

( Pdf, E-pub, Full Text, Audio)

- Unceasing customer service

Track the below URL for one-step submission https://juniperpublishers.com/online-submission.php 